\title{
The Association of Dynamin with Synaptophysin Regulates Quantal Size and Duration of Exocytotic Events in Chromaffin Cells
}

\author{
Arlek M. González-Jamett, Ximena Báez-Matus, Montserrat A. Hevia, María José Guerra, María José Olivares, \\ Agustín D. Martínez, Alan Neely, and Ana M. Cárdenas \\ Centro Interdisciplinario de Neurociencia de Valparaíso, Universidad de Valparaíso, Playa Ancha, Valparaíso 2340000, Chile
}

\begin{abstract}
Although synaptophysin is one of the most abundant integral proteins of synaptic vesicle membranes, its contribution to neurotransmitter release remains unclear. One possibility is that through its association with dynamin it controls the fine tuning of transmitter release. To test this hypothesis, we took advantage of amperometric measurements of quantal catecholamine release from chromaffin cells. First, we showed that synaptophysin and dynamin interact in chromaffin granule-rich fractions and that this interaction relies on the $\mathrm{C}$ terminal of synaptophysin. Experimental maneuvers that are predicted to disrupt the association between these two proteins, such as injection of antibodies against dynamin or synaptophysin, or peptides homologous to the $C$ terminal of synaptophysin, increased the quantal size and duration of amperometric spikes. In contrast, the amperometric current that precedes the spike remained unchanged, indicating that synaptophysin/dynamin association does not regulate the initial fusion pore, but it appears to target a later step of exocytosis to control the amount of catecholamines released during a single vesicle fusion event.
\end{abstract}

\section{Introduction}

As for neurotransmitter release at synapses, catecholamine release from adrenal chromaffin cells requires the concerted action of protein complexes that mobilize the secretory vesicle to the release site, fuse the vesicle membrane with the plasma membrane, empty its content, and retrieve the vesicle membrane for recycling. Being one of the most abundant integral proteins of synaptic vesicle membranes (Jahn et al., 1985), synaptophysin has been proposed to participate at several stages of the vesicle life cycle (Valtorta et al., 2004). This protein is also present in secretory granules of adrenal chromaffin cells (Obendorf et al., 1988; Schilling and Gratzl, 1988; Fournier et al., 1989) but at a lower density compared with synaptic vesicle membranes (Schilling and Gratzl, 1988).

Synaptophysin is composed of four transmembrane domains and cytosolic C and N termini (Südhof et al., 1987). The functional role of this protein has been controversial. Early studies supported the idea that synaptophysin was a component of the fusion pore formed during exocytosis (Thomas et al., 1988) and that it played a central role in neurotransmitter release (Alder et al., 1992a, 1992b; Yin et al., 2002). However, this idea was incon-

Received 0ct. 20, 2009; revised June 18, 2010; accepted June 27, 2010.

This work was supported by Fondecyt 1085266, DIPUV 08/2006, Anillo de Ciencia y Tecnología (ACT 46), and Proyecto PBCT Redes 24. We thankF. Vargas for his assistance in the electron microscopy, A. Ardiles for helping in the immunodetection of C-term $240-290$, Dr. P. Hidalgo (Hannover Medizinishe Hocheshule, Hannover, Germany) for providing the GST protein, Dr. R. E. Leube (University of Mainz, Mainz, Germany) for providing the synapotophysin CDNA, and Frigorifico Don Pedro for providing bovine adrenal glands.

Correspondence should be addressed to Ana M. Cárdenas, Centro Interdisciplinario de Neurociencia de Valparaíso, Universidad de Valparaíso, Avenida Gran Bretaña 1111, Playa Ancha, Valparaíso 2340000, Chile. E-mail:ana.cardenas@uv.cl.

DOI:10.1523/JNEUROSCI.5210-09.2010

Copyright $\odot 2010$ the authors $\quad 0270-6474 / 10 / 3010683-09 \$ 15.00 / 0$ sistent with the lack of a neurotransmitter release phenotype of synaptophysin knock-out mice (McMahon et al., 1996). One possible explanation is the inherent redundancy of the system, which expresses related proteins such as synaptoporin and synaptogyrin (Janz et al., 1999; Spiwoks-Becker et al., 2001). More recent findings implicate synaptophysin in the rapid retrieval of synaptic vesicles through its association with dynamin (Daly et al., 2000; Daly and Ziff, 2002). The hypothesis set forth by these authors is that synaptophysin recruits the GTPase dynamin to the release site in a calcium-dependent manner to promote the rapid retrieval of synaptic vesicles (Daly et al., 2000). In chromaffin cells, disruption of dynamin GTPase activity increases the amount of catecholamines released per individual exocytotic event (Graham et al., 2002). These findings indicate that dynamin plays a pivotal role in controlling the amount of transmitters released during a single exocytotic event. However, the mechanism by which dynamin controls the quantal size $(\mathrm{Q})$ remains unknown. To get additional insight into this mechanism, we characterized the interaction between synaptophysin and dynamin in chromaffin cells, and, taking advantage of the carbon-fiber amperometry technique, we studied how the disruption of the association between these proteins affects individual exocytotic events. Our results show that synaptophysindynamin association controls the quantal size and the duration of the exocytotic events. However, the amperometric current that precedes the amperometric spike remains unchanged, indicating that the synaptophysin-dynamin association does not regulate the initial fusion pore, but would become involved in a later step of exocytosis. This yet-to-be-identified step would control the amount of catecholamines released during a single vesicle exocytotic event. 


\section{Materials and Methods}

Cloning, expression, and purification of $C$ terminal of synaptophysin. The plasmid Bluescript II SK containing the complete cDNA of synaptophysin was a gift from Dr. Rudolf E. Leube (University of Mainz, Mainz, Germany). The region encoding the C-terminal domain of synaptophysin (from amino acid 219 to amino acid 307) was amplified by PCR using the forward primer ( $5^{\prime}$-AAGGAGACAGGCTGGGCAGCC-3') and reverse primer (5' ${ }^{\prime}$ TTACATCTGATTGGAGAAGGAGGTGGG-3') complementary to nucleotides 664-684 and 907-933 of the rat coding sequence, respectively (Leube et al., 1987). The resulting PCR product was digested with BamHI and EcoRI and subcloned into the expression plasmid pGEX-4T2 (GE Healthcare) and verified by DNA sequencing. The resulting clone was expressed in Escherichia coli BL21 cells according to standard methods, and the glutathione $S$-transferase (GST) fusion protein (GST-Cterm) was purified by batch binding from cell lysates to glutathione agarose beads (Invitrogen). GST protein was a gift from Dr. Patricia Hidalgo (Hannover Medizinishe Hocheshule, Hannover, Germany).

Synthesis of a synthetic peptide homologous to synaptophysin C terminal. We designed a synthetic peptide homologous to a region of the $\mathrm{C}$ terminal of bovine synaptophysin (amino acids 240-290) that contains the segment necessary to interact with dynamin (Daly and Ziff, 2002) and with the monoclonal antibody against synaptophysin clone SY-38 (Knaus and Betz, 1990). For synthesis requirement, this peptide contains a deletion of six amino acids (265-270), but for simplicity we called it C-term $_{240-290}$ (for sequence, see Fig. 4A). This peptide was synthesized by Invitrogen. The immunoreactivity of C-term ${ }_{240-290}$ to the antisynaptophysin antibody (clone SY-38) was confirmed by Western blot after being subjected to electrophoresis on $12 \%$ SDS-polyacrylamide Tris-tricine gels (see Fig. $4 D$, inset).

Cell cultures and microinjections. Bovine adrenal chromaffin cells were isolated as previously described (Montiel et al., 2003). Briefly, cells were suspended in 1:1 mixture of DMEM and Ham's F-12 (DMEM-F12) supplemented with $10 \%$ fetal calf serum, $50 \mathrm{IU} / \mathrm{ml}$ penicillin, and 100 $\mu \mathrm{g} / \mathrm{ml}$ gentamicin. Cells were plated on 25 -mm-diameter glass coverslips at a density of $2.5 \times 10^{4}$ cells $/ \mathrm{ml}$. Cells were kept in a water-saturated incubator at $37^{\circ} \mathrm{C}$, in a $5 \% \mathrm{CO}_{2} / 95 \%$ air atmosphere, and used in the experiments after $2-4 \mathrm{~d}$ of culture.

Chromaffin cells were injected using an InyectMan NI2 system (Eppendorf) and glass micropipettes with an internal tip diameter of $0.5 \mu \mathrm{m}$ (Femtotips, Eppendorf). The injection time was $0.2 \mathrm{~s}$ at a pressure of 120 $\mathrm{hPa}$. During microinjection, chromaffin cells were kept in DMEM-F12 without $\mathrm{HCO}_{3}$ to avoid changes in $\mathrm{pH}$.

The monoclonal antibodies against dynamin (anti-Dyn, BD Bioscience), synaptophysin, clone SY-38 (anti-Syn, Millipore Bioscience Research Reagents), poly-His (anti-His, Covance), and C-term ${ }_{240-290}$ were injected at an approximate concentration of $10 \mu \mathrm{M}$. The GST-Cterm was injected at 10 and $40 \mu \mathrm{M}$.

Amperometric detection of exocytosis. The exocytotic release of catecholamines was detected by amperometry, as previously described (Ardiles et al., 2006). Carbon fibers of $5 \mu \mathrm{m}$ radius (Thornel P-55, Amoco) were used to manufacture the microelectrodes (Kawagoe et al., 1993). Electrochemical recordings were performed using an Axopatch 1C patch-clamp amplifier modified for this purpose according to the manufacturer instructions (Molecular Devices). Cells were placed in a perfusion chamber positioned on the stage of an inverted microscope and washed in Krebs-HEPES buffer solution (in mM: $140 \mathrm{NaCl}, 5 \mathrm{KCl}, 2$ $\mathrm{MgCl}_{2}, 2.5 \mathrm{CaCl}_{2}, 10 \mathrm{HEPES}-\mathrm{NaOH}$, and 10 glucose, $\mathrm{pH}$ 7.4). Catecholamine release was stimulated by $10 \mathrm{~s}$ pressure ejection of $100 \mathrm{~mm} \mathrm{~K}{ }^{+}$ solution from a micropipette positioned $10-15 \mu \mathrm{m}$ from the cell. Amperometric records were low pass filtered at $1 \mathrm{kHz}$ and digitized at $5 \mathrm{~Hz}$ with a PCI-6030E analog-to-digital converter (National Instruments) controlled by WinEDR software (University of Strathclyde). Data analysis was carried out using locally written macros for IGOR (Wavemetrics). These macros allowed the automatic digital filtering, secretory spike identification, and data analysis (Segura et al., 2000). All of the above macros and their user instructions can be downloaded from the following Web address: http://webpages.ull.es/users/rborges/. Spikes with am- plitude $<15 \mathrm{pA}$ or rise time $>15 \mathrm{~ms}$ as well as overlapping spikes were excluded from the analysis. Foot analysis was restricted to events with current and duration $>2 \mathrm{pA}$ and $>2 \mathrm{~ms}$, respectively.

Subcellular fractionation of chromaffin cells. Chromaffin cells were centrifuged at $1000 \times g$ for $10 \mathrm{~min}$, and the pellet was resuspended in a buffer solution containing: $0.32 \mathrm{M}$ sucrose, protease inhibitor mixture (Roche Applied Science), $10 \mathrm{~mm}$ Tris- $\mathrm{HCl}, \mathrm{pH}$ 7.4. Then the supernatant was centrifuged at $20,000 \times g$ for $20 \mathrm{~min}$, and the pellet was layered over a continuous sucrose density gradient $(1-2.2 \mathrm{M})$. Gradients were centrifuged at $4^{\circ} \mathrm{C}$ for $1 \mathrm{~h}$ at $100,000 \times g$ in a Beckman Optima XL-100 K ultracentrifuge. Fractions of $300 \mu \mathrm{l}$ were then collected from the bottom to top; aliquots were taken for immunoblotting analysis.

Chromaffin granules were purified from the $20,000 \times g$ pellet using 1.6 M sucrose gradients (Smith and Winkler, 1967). The chromaffin granule-enriched fraction was solubilized in cold hypotonic buffer $(1 \mathrm{mM}$ HEPES/Na, $\mathrm{pH} 7.0$, and protease inhibitor mixture) and centrifuged again at $100,000 \times g$ for $1 \mathrm{~h}$. The pellet was then resuspended in cold hypotonic buffer for immunoblotting analysis.

Immunoprecipitation and pull-down assays. Proteins from chromaffin cells were extracted at $4^{\circ} \mathrm{C}$ in a lysis buffer $(150 \mathrm{~mm} \mathrm{NaCl}, 20 \mathrm{~mm}$ HEPES, 5 mм EDTA, pH 7.4, 1\% Triton X-100) containing a protease inhibitor mixture (Roche Applied Science). In some experiments, EDTA was replaced by $2 \mathrm{~mm}$ EGTA or $2 \mathrm{~mm} \mathrm{CaCl}_{2}$ and $2 \mathrm{~mm} \mathrm{MgCl}_{2}$ in the lysis buffer. For immunoprecipitation assays, $1 \mu \mathrm{g}$ of anti-Dyn, anti-Syn, or a polyclonal antibody against amino acids 41-62 of human synaptophysin (Abcam) was incubated for $2 \mathrm{~h}$ with $30 \mu \mathrm{l}$ of A-Sepharose $4 \mathrm{~B}$ beads (Invitrogen). After binding, the beads were washed three times in lysis buffer. Then, the antibody bound to the Sepharose beads were incubated for $1 \mathrm{~h}$ at $4^{\circ} \mathrm{C}$ with $800 \mu \mathrm{g}$ of protein extracts in the presence of $10 \%$ bovine serum albumin. Bound proteins were eluted in SDS sample buffer and analyzed by immunoblotting for synaptophysin, dynamin, or vesicle-associated membrane protein 2 (VAMP-2). VAMP-2 was identified with a polyclonal antibody (Novus Biologicals).

For pull-down assays, $100 \mu \mathrm{l}$ of glutathione-agarose beads (Invitrogen) were incubated with $120 \mu \mathrm{g}$ of GST or GST-Cterm for $5 \mathrm{~h}$ at $4^{\circ} \mathrm{C}$. Then, the GST fusion proteins immobilized on glutathioneagarose beads were incubated overnight at $4^{\circ} \mathrm{C}$ with $800 \mu \mathrm{g}$ of protein extracts. After binding, the beads were washed three times in lysis buffer. Bound proteins were eluted in SDS sample buffer and analyzed by immunoblotting.

Statistics. Results were expressed as means \pm SEM. Amperometric spike data were grouped by individual cells; thus, the data presented correspond to means \pm SEM of cell averages, and " $n$ " refers to the number of cells. Statistical comparisons were performed using the nonparametric Mann-Whitney $U$ test.

\section{Results}

\section{Synaptophysin is a partner of dynamin in chromaffin granules}

To characterize the interaction between synaptophysin and dynamin in chromaffin cells, we performed immunoprecipitation and pull-down assays, and analyzed the presence of both proteins in chromaffin granule membranes. As shown in Figure $1 \mathrm{~A}$, immunoprecipitation with the anti-Dyn antibody precipitated a comparable amount of synaptophysin from chromaffin cell extracts in the presence of $\mathrm{Ca}^{2+} / \mathrm{Mg}^{2+}$ or EGTA. Densitometric analysis of immunoblots obtained from six independent experiments shows nonsignificant differences for synaptophysin precipitated in both conditions. Thus, contrary to that observed in brain extracts (Daly and Ziff, 2002), in chromaffin cells free $\mathrm{Ca}^{2+}$ does not appear to influence synaptophysin-dynamin interaction, at least in vitro. This does not rule out though that cytosolic $\mathrm{Ca}^{2+}$ may regulate this interaction in vivo. Therefore, we immunoprecipitated cell extracts obtained immediately after depolarizing the cells with $100 \mathrm{~mm} \mathrm{KCl}$ for 5 min (Fig. 1 B). Densitometric analysis of immunoblots from nine experiments shows a $62 \pm$ $15 \%$ increase in the amount of immunoprecipitated synaptophy- 


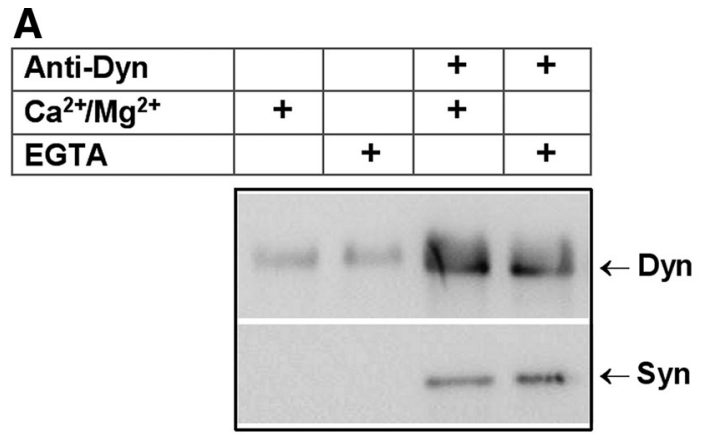

B

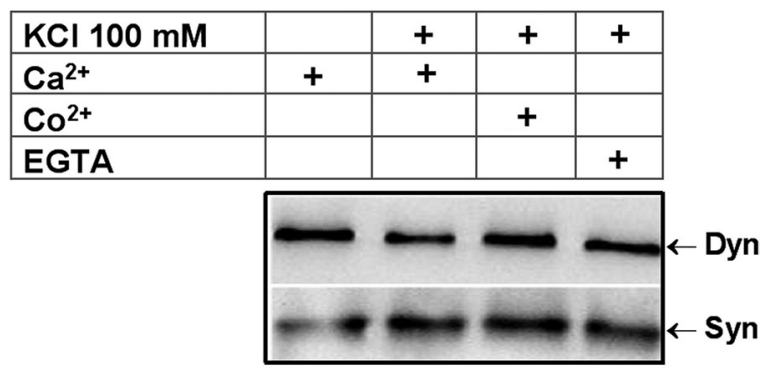

C

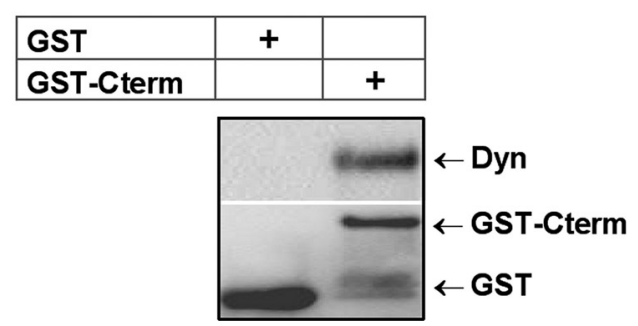

Figure 1. Synaptophysin binds to dynamin in bovine chromaffin cells. $A$, Protein extracts from cultured bovine chromaffin cells were incubated in the presence of $\mathrm{Ca}^{2+}$ / $\mathrm{Mg}^{2+}$ or EGTA for $30 \mathrm{~min}$, and then subjected to immunoprecipitation with a monoclonal anti-dynamin antibody. Bound proteins were analyzed by immunoblotting with anti-Dyn and anti-Syn antibodies. $\boldsymbol{B}$, Protein extracts from non-depolarized chromaffin cells, or cells depolarized with $100 \mathrm{~mm} \mathrm{KCl} \mathrm{(5} \mathrm{min)} \mathrm{in} \mathrm{the} \mathrm{presence} \mathrm{of} 2.5 \mathrm{~mm} \mathrm{Ca}^{2+}, 5 \mathrm{~mm}$ EGTA, or $10 \mathrm{~mm} \mathrm{CO}{ }^{2+}$ were immunoprecipitated with a monoclonal anti-dynamin antibody. EGTA and $\mathrm{CO}^{2+}$ were present $15 \mathrm{~min}$ before and during the depolarizing pulse. Bound proteins were analyzed by immunoblotting with antibodies against Syn and Dyn. C, GST alone or GST-Cterm was immobilized on glutathione-agarose beads and incubated with protein extracts from chromaffin cells. The bound material was subjected to immunobloting with anti-Dyn and anti-GST antibodies.

sin from extracts from depolarized cells. To test whether $\mathrm{Ca}^{2+}$ entry was mediating this increase, we depolarized the cells in the presence of EGTA or $\mathrm{Co}^{2+}$, a nonspecific calcium channel blocker. Surprisingly, we found that the EGTA or $\mathrm{Co}^{2+}$ treatment did not inhibit the depolarization-induced increase of synaptophysin-dynamin interaction (Fig. $1 B$ ). The analysis of five experiments shows nonsignificant differences.

In brain extract, synaptophysin was shown to interact with dynamin through its C-terminal domain (Daly and Ziff, 2002). Here, to confirm that in chromaffin cells the $\mathrm{C}$ terminal of synaptophysin was also mediating this interaction, we used a GST fusion protein comprising the $\mathrm{C}$ terminal of synaptophysin (GST-Cterm) to pull down dynamin. As shown in Figure $1 C$, GST-Cterm binds dynamin from chromaffin cell extracts.

To investigate in which cellular compartment the dynaminsynaptophysin interaction occurs we analyzed the subcellular distribution of these proteins. To this end, cellular extracts were
A

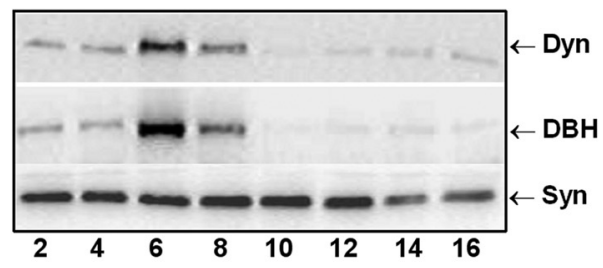

B

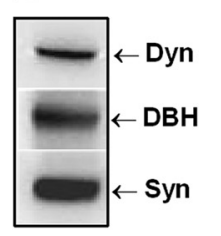

C
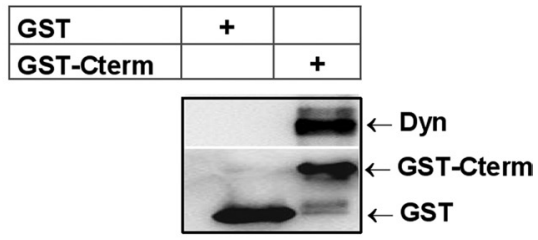

D

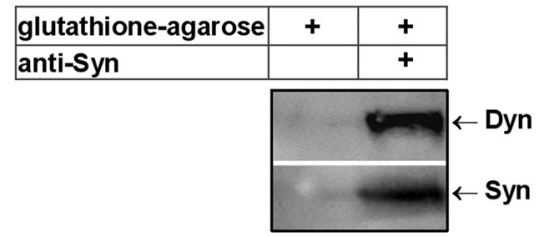

E

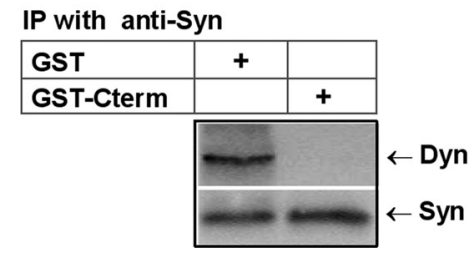

Figure 2. Immunodetection of dynamin and synaptophysin in chromaffin granules. $\boldsymbol{A}$, Fractions 2-16 collected from a continuous sucrose density gradient (1.0-2.2 m sucrose) layered with protein extracts from chromaffin cells were subjected to gel electrophoresis and immunodetected with anti-Dyn, anti-DBH, and anti-Syn. $\boldsymbol{B}$, Purified chromaffin granule membranes were subjected to immunoblotting with anti-Dyn, anti-DBH, and antiSyn. C, GST alone or GST-Cterm were immobilized on glutathione-agarose beads and incubated with protein extracts from chromaffin granules. The bound material was subjected to immunobloting with anti-Dyn and anti-GST antibodies. D, Chromaffin granule extracts were subjected to immunoprecipitation with anti-Syn. Bound proteins were analyzed by immunoblotting with anti-Dyn and anti-Syn. $\boldsymbol{E}$, Supernatants from pull-down assays were subjected to immunoprecipitation with anti-Syn, and then bound proteins were analyzed by immunoblotting with anti-Dyn and anti-Syn.

layered on a continuous sucrose density gradient $(1.0-2.2 \mathrm{M} \mathrm{su}-$ crose), ultracentrifuged at $100,000 \times g$ for $1 \mathrm{~h}$ and collected in 16 fractions that were assayed by immunoblot for dynamin, synaptophysin, and dopamine $\beta$-hydroxylase (DBH), a standard chromaffin granule marker. As shown in Figure $2 A$, the distribution of dynamin correlated quite well with the distributions of $\mathrm{DBH}$ (fractions 6-8), confirming its association with chromaffin granules. A similar distribution of dynamin in bovine chromaffin cells was previously observed by Galas et al. (2000). In contrast, synaptophysin is broadly distributed across the sucrose density gradients. This result is consistent with synaptophysin being present not only in chromaffin granules (Obendorf et al., 1988; Schilling and Gratzl, 1988; Fournier et al., 1989) but also in other organelles such as synaptic-like microvesicles (Annaert et al., 1993), trans-Golgi networks (Régnier-Vigouroux et al., 1991), endosomes (Tixier-Vidal et al., 1988), and recycling vesicular organelles (Cameron et al., 1991; Linstedt and Kelly, 1991).

We also analyzed the presence of dynamin and synaptophysin in membranes isolated from purified chromaffin granules and investigate whether these proteins interact in these organelles. As 
shown in Figure $2 B$, dynamin and synaptophysin are present in chromaffin granule membranes, and both GST-Cterm and anti-Syn antibody efficiently bind dynamin from granule extracts (Fig. 2C,D). Interestingly, when the supernatants obtained from the pull-down assays were subjected to an immunoprecipitation using the anti-Syn antibody, we observed that no dynamin was immunoprecipitated from the supernatant obtained from the GSTCterm pull-down assay (Fig. 2E). This result suggests that in chromaffin granules most dynamin is found as a dynamin-synaptophysin complex.

\section{Microinjections of antibodies against synaptophysin or dynamin increase duration and quantal size of the exocytotic events}

To investigate the role of synaptophysindynamin association in exocytosis, we injected chromaffin cells with proteins that interfere with either the function or association of these proteins. Compared with DNA transfection or protein dialysis via a patch pipette, microinjection of purified proteins is particularly well suited to study acute effects without affecting the cytosol composition. Exocytosis was monitored by amperometry, a technique that allows monitoring individual exocytotic events in real time as amperometric spikes. The time course and area of these spikes yield information about the kinetics and the mode of exocytosis (Fisher et al., 2001; Ardiles et al., 2007).

Figure $3 A$ shows representative amperometric traces from experiments performed in chromaffin cells noninjected (control) or injected with anti-Syn. Figure $3 B$ compares the cumulative histograms of the number of amperometric events from both conditions. A $10 \mathrm{~s}$ pulse of high $\mathrm{K}^{+}$produced $65 \pm 8(n=24)$ amperometric spikes over a period of $100 \mathrm{~s}$ in control cells. A similar number of exocytotic events evoked by high $\mathrm{K}^{+}$was observed in cells injected with anti-Syn (51 \pm 6 exocytotic events in 100 s). However, as shown in Figure $3 C$, the shape and size of the individual amperometric spikes appear modified by anti-Syn intracellular injection. Figure $3 D$ summarizes the amperometric parameters analyzed: (1) the Q, which is proportional to the amount of catecholamines released during each exocytotic event; and (2) the half-width $\left(t_{1 / 2}\right)$ that reflects the duration of the individual exocytotic events. As shown in Figure 3E, Q was significantly larger in anti-Syn injected cells $(2.0 \pm 0.16 \mathrm{pC})$ than control cells $(1.3 \pm 0.1 \mathrm{pC})$. The injection of anti-Syn also slowed $\mathrm{t}_{1 / 2}$ significantly. Mean values for $\mathrm{t}_{1 / 2}$ were $14 \pm 0.8 \mathrm{~ms}$ for control, and $19 \pm 0.9 \mathrm{~ms}$ for anti-Syninjected cells. We also analyzed other amperometric parameters, such as the peak amplitude (Imax), corresponding to the maximum concentration reaching the carbon electrode; the rise time, influenced by the size and expansion rate of the fusion pore with control cells.
B

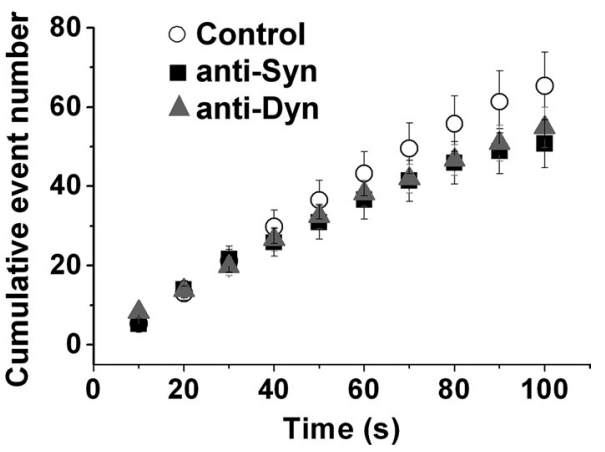

D

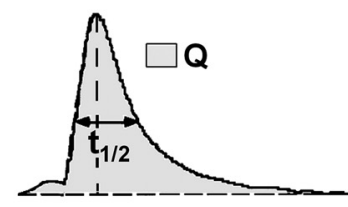

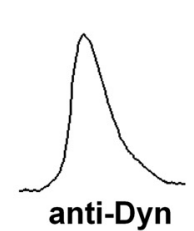

anti-Syn

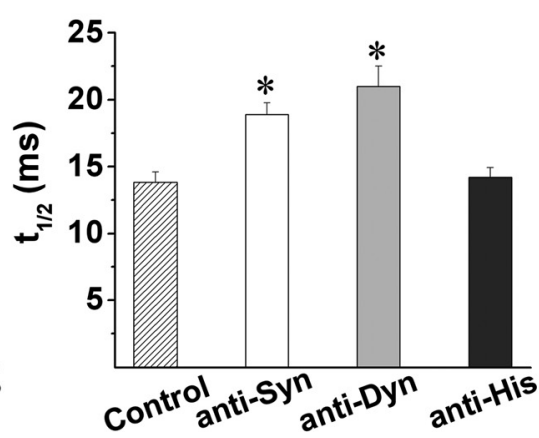

Figure 3. Microinjections of antibodies against synaptophysin or dynamin increase duration and quantal size of depolarizationinduced exocytotic events. Chromaffin cells were injected with anti-Syn, anti-Dyn or anti-His. The exocytosis response was evoked by high $\mathrm{K}^{+}$and measured $30-45$ min after injections. $A$, Representative amperometric traces from noninjected cells (Control) or (with anti-Syn. B, Cumulative histograms of the number of amperometric events from control (white circes), anti-Syn trol), anti-Syn and anti-Dyn injected cells. $\boldsymbol{D}$, Representative amperometric spike with its parameters: $\mathbf{Q}$ and $\mathrm{t}_{1 / 2}$. $\boldsymbol{E}$, Averaged values for $Q$ and $t_{1 / 2}$. Data are means \pm SEM of averages per cell ( $14-24$ cells from 3 to 5 different cultures). ${ }^{*} p<0.05$ compared

(Neco et al., 2008); and the decay time, which reflects depletion of catecholamines. The latter parameter seems to be accelerated by the premature closure of the fusion pore (Elhamdani et al., 2001; Graham et al., 2002; Barclay et al., 2003). As shown in Table 1, injection of the anti-Syn significantly slowed the decay time, while the rise time and Imax remain unchanged.

We also evaluated the effect of intracellular injection of antiDyn. Injection of this antibody did not affect the number of exocytotic events significantly ( $55 \pm 5$ ) (Fig. $3 B$ ). However, compared with noninjected control cells (Fig. 3E), anti-Dyn injection significantly increased $\mathrm{Q}$ and $\mathrm{t}_{1 / 2}(2.0 \pm 0.19 \mathrm{pC}$ and $21 \pm 1.5 \mathrm{~ms}$, respectively). As observed for anti-Syn, anti-Dyn also slowed the decay time, but neither Imax nor the rise time were affected (Table 1). These results agree with previous findings in chromaffin cells showing that disruption of dynamin function increases both catecholamine quantal size and duration of exocytotic events (Graham et al., 2002).

As a control for specificity of anti-Syn and anti-Dyn effects, we injected cells with an antibody against an antigen not present in 
Table 1. Amperometric spike parameters from chromaffin cells in different experimental conditions

\begin{tabular}{lllc}
\hline & $\operatorname{Imax}(\mathrm{pA})$ & Rise time $(\mathrm{ms})$ & Decay time $(\mathrm{ms})$ \\
\hline Control & $83 \pm 4$ & $5.2 \pm 0.3$ & $7.7 \pm 0.5$ \\
Anti-Syn $(10 \mu \mathrm{M})$ & $81 \pm 7$ & $5.9 \pm 0.5$ & $10.6 \pm 0.8^{*}$ \\
Anti-Dyn $(10 \mu \mathrm{M})$ & $78 \pm 6$ & $5.4 \pm 0.4$ & $10.3 \pm 0.7^{*}$ \\
Anti-His $(10 \mu \mathrm{M})$ & $77 \pm 4$ & $5.5 \pm 0.4$ & $8.1 \pm 0.4$ \\
GST $(40 \mu \mathrm{M})$ & $88 \pm 8$ & $4.8 \pm 0.3$ & $7.3 \pm 0.5$ \\
GST-Cterm $(10 \mu \mathrm{M})$ & $95 \pm 4^{*}$ & $4.9 \pm 0.4$ & $8.6 \pm 0.6$ \\
GST-Cterm + anti-Syn $(10 \mu \mathrm{M})$ & $89 \pm 5$ & $4.7 \pm 0.2$ & $7.2 \pm 0.4$ \\
GST-Cterm $(40 \mu \mathrm{M})$ & $89 \pm 4$ & $4.8 \pm 0.4$ & $11.9 \pm 0.6^{*}$ \\
GST-Cterm + anti-Syn $(40 \mu \mathrm{M})$ & $90 \pm 9$ & $4.5 \pm 0.5$ & $7.1 \pm 0.6$ \\
C-term $_{240-290}(10 \mu \mathrm{M})$ & $92 \pm 4$ & $5.7 \pm 0.5$ & $10.6 \pm 1.0^{*}$ \\
C-term $_{240-290}+$ anti-Syn $(10 \mu \mathrm{M})$ & $85 \pm 9$ & $5.0 \pm 0.3$ & $7.1 \pm 0.3$ \\
\hline
\end{tabular}

Control cells correspond to noninjected cells. Cells were injected with monoclonal anti-Syn, anti-Dyn, or anti-His antibodies. Cells were also injected with the following peptides: GST, GST-Cterm, and C-term $240-290$. Peptides encompassing the C terminal of synaptophysin were also coinjected with anti-Syn (GST-Cterm + anti-Syn; (-term $240-290+$ anti-Syn). Rise time, Time needed to reach Imax; Decay time, time constant of a single exponential fit to the decay phase. Data are means \pm SEM of cell median for each spike parameters (12-24 cells from 3-5 different cultures). ${ }^{*} p<0.05$ compared with control cells.

chromaffin cells such as a standard polyhistidine tag (anti-His). Anti-His injected at the same concentration used for the other antibodies $(10 \mu \mathrm{M})$ did not modify any of the different amperometric parameters (Fig. 3E, Table 1).

\section{Disruption of synaptophysin-dynamin association with the C terminal of synaptophysin increases duration and quantal size of depolarization-induced exocytotic events}

To disrupt the association between synaptophysin and dynamin, we injected chromaffin cells with GST-Cterm or C-term $240-290$, a synthetic peptide homologous to the $\mathrm{C}$-terminal region of bovine synaptophysin encompassing both the minimal region necessary to interact with dynamin (Daly and Ziff, 2002) and the anti-Syn epitope (Knaus and Betz, 1990). Figure 4A shows the amino acid sequences of the C-terminal domain of rat synaptophysin used to construct GST-Cterm fusion protein, and the synthetic peptide C-term $240-290$. To demonstrate that these peptides indeed disrupt the synaptophysin-dynamin association, we immunoprecipitated with a polyclonal antibody against amino acids 41-62 of human synaptophysin protein extracts incubated with $10 \mu \mathrm{M}$ GST-Cterm or C-term ${ }_{240-290 .}$. As shown in Figure $4 B$, coprecipitation of dynamin was considerably diminished in the presence of both peptides. Coprecipitation of dynamin decreased by $62 \pm 10 \%(n=4)$ and $78 \%(n=2)$ in the presence of GST-Cterm or C-term $240-290$, respectively. As a control, we evaluated the effect of these peptides on the coprecipitation of VAMP-2, a known partner of synaptophysin in synaptic vesicles. The analysis shows that VAMP-2 coprecipitation was not affected in the presence of GST-Cterm or C-term ${ }_{240-290}$. VAMP-2/synaptophysin ratios were $1.02 \pm 0.07(n=4)$ and $1.12(n=2)$.

Cumulative histograms of the number of events show that the intracellular injection of either GST-Cterm or C-term ${ }_{240-290}$ did not modify significantly the number of the exocytotic events induced by high $\mathrm{K}^{+}$(Fig. 4C). Over a period of 100 s, GST-Cterminjected cells $(40 \mu \mathrm{M})$ and C-term $240-290$-injected cells $(10 \mu \mathrm{M})$ produced $56 \pm 9(n=19)$ and $52 \pm 6(n=18)$ amperometric spikes, respectively. Figure $4 D$ shows representative amperometric spikes of cells injected with either GST alone, GST-Cterm, or C-term $240-290$. The analysis of the amperometric parameters revealed that injection of GST-Cterm modified Q in a concentration-dependent manner (Fig. 4E). Q values for 10 and 40 $\mu \mathrm{M}$ GST-Cterm were $2.1 \pm 0.2$ and $2.6 \pm 0.2 \mathrm{pC}$, respectively. These $Q$ values were significantly higher than those from cells injected with GST alone ( $p<0.05)$. Q value for GST alone was $1.4 \pm 0.13$ pC. As shown in Figure 4E, GST-Cterm, at both concentrations, also slowed $t_{1 / 2}$ significantly, compared with cells injected with GST alone $(p<0.05)$. For 10 and $40 \mu \mathrm{M}$ of GSTCterm, $\mathrm{t}_{1 / 2}$ values were $15 \pm 1.2$ and $20 \pm 0.9 \mathrm{~ms}$, respectively. Only at $40 \mu \mathrm{M}$, GST-Cterm slowed the decay time significantly ( $p<0.05$ compared with GST alone and control cells; Table 1$)$. The rise time was not affected by both concentrations of GSTCterm, but compared with noninjected cells at $10 \mu \mathrm{M}$ this recombinant protein increased Imax significantly (Table 1). As shown in Figure $4 E, C$-term ${ }_{240-290}(10 \mu \mathrm{M})$ increased Q $(2.0 \pm 0.1 \mathrm{pC})$ and $\mathrm{t}_{1 / 2}(20 \pm 2 \mathrm{~ms})(p<0.05$ compared with controls). Compared with control cells, this peptide also slowed the decay time significantly, but it did not modify Imax or the rise time (Table 1 ).

The epitope recognized by anti-Syn is located in the C-terminal tail of synaptophysin, which was confirmed by the Western blots shown in Figure $4 E$ as insets. Therefore, the specificity of the effects of both antibody and peptides was tested by injecting anti-Syn preincubated with either GST-Cterm or C-term $240-290$. As shown in Figure $4 E$, coinjection of anti-Syn with either GST-Cterm or C-term ${ }_{240-290}$ did not modify the amperometric parameters.

\section{The acute disruption of synaptophysin-dynamin association} does not affect the fusion pore dynamics

Preceding the amperometric spike of a standard exocytotic event, it is often possible to detect a small stepwise current usually referred to as "foot" that reflects the slow release of catecholamines through a narrow fusion pore (Chow et al., 1992). The amplitude of the foot currents is proportional to the fusion pore conductance (Albillos et al., 1997), whereas the duration of the foot signal is thought to reflect the stability of the fusion pore (Lindau and Alvarez de Toledo, 2003). Here, we examined the effects of GST-Cterm, C-term $240-290$, and anti-Syn on the frequency, duration, and amplitude of foot signals. Figure $5 B$ shows examples of amperometric spikes from controls and cells injected with GST, GST-Cterm, C-term ${ }_{240-290}$, or anti-Syn. As shown in Figure 5C, $37 \pm 4 \%$ of the amperometric spikes from control cells exhibited feet with an average duration and amplitude of $21 \pm 2 \mathrm{~ms}$ and $17 \pm 1 \mathrm{pA}$, respectively. The injection of GST, GST-Cterm, C-term $240-290$, or anti-Syn did not affect the frequency, amplitude, and duration of foot signals (Fig. 5C).

\section{Discussion}

In the present article, we studied the interaction of synaptophysin with dynamin in chromaffin cells and showed that synaptophysin is a partner of dynamin in chromaffin granules, and that disruption of the association between these proteins increases the quantal size and duration of individual exocytotic events.

\section{Synaptophysin and dynamin are constitutively associated in chromaffin cells}

In contrast to a previous study in brain synaptosomes (Daly and Ziff, 2002) using the same protocol, we observed that in chromaffin cells synaptophysin-dynamin interaction occurs in vitro independently of the presence of $\mathrm{Ca}^{2+}$ (Fig. 1A). We also show that also in vivo this interaction does not depend on cytosolic $\mathrm{Ca}^{2+}$ (Fig. $1 B$ ). The lack of $\mathrm{Ca}^{+2}$ dependence may stem from differ- 
ences in the type of dynamin involved. Neurons express mostly dynamin-1, whereas chromaffin cells mainly express dynamin-2 (Galas et al., 2000). These two isoforms differ in their capability to interact with other proteins. Dynamin-2, for example, binds more efficiently to the postsynaptic protein Shank than dynamin-1 (Okamoto et al., 2001). In addition, each dynamin isoform has at least four alternatively spliced variants (Cao et al., 1998), and these splicings may also display differences in their affinities for partner proteins (McNiven et al., 2000).

A curious feature of the dynaminsynaptophysin association in chromaffin cells is that the interaction in vivo between these proteins is favored by cell depolarization, but this effect is independent of $\mathrm{Ca}^{2+}$ entry. We still have not been able to identify a $\mathrm{Ca}^{2+}$-independent mechanism for the depolarization-induced increase in dynamin-synaptophysin association. One possibility is suggested by the observation that membrane depolarization provoked by high $\mathrm{K}^{+}$produces intracellular acidification in rat hippocampal slices (Zhan et al., 1998). This effect, only partially dependent on extracellular $\mathrm{Ca}^{2+}$, was proposed to stem from a metabolic accumulation of lactate secondary to an increased $\mathrm{Na}^{+}-\mathrm{K}^{+}$ATPase activity. It is plausible that membrane depolarization of chromaffin cells also changes the cytosolic $\mathrm{pH}$ by a similar mechanism and that this acidification impacts dynamin-synaptophysin association.

Our results also indicate that synaptophysin and dynamin are constitutively associated in chromaffin cells and that this interaction seems important to keep dynamin bound to the chromaffin granules. Indeed, our results show that synaptophysin and dynamin are present in chromaffin granules (Fig. $2 A, B$ ), and that both anti-Syn and GST-Cterm efficiently bind dynamin from granule extracts (Fig. 2C,D). As shown by the distribution of these proteins in a continuous sucrose density gradient, synaptophysin is also present in other organelles, whereas dynamin cosediments with synaptophysin only in the chromaffin granule fraction (Fig. $2 A$ ). This preferential colocalization of dynamin with synaptophysin in chromaffin granule could be a consequence of: (1) other proteins present in the granules, such as syntaxin, contributing to the association of dynamin to chromaffin granules ( $\mathrm{Ga}$ las et al., 2000); and/or (2) the lipid composition of the granule membranes favoring the associations between synaptophysin and dynamin. The latter idea is supported by the observation that cholesterol content is higher in granules than in synaptic-like microvesicles such as those found in PC12 cells (Wang et al., 2006) and that cholesterol content regulates the association of synaptophysin with other proteins, such as synaptobrevin (Mitter et al., 2003).

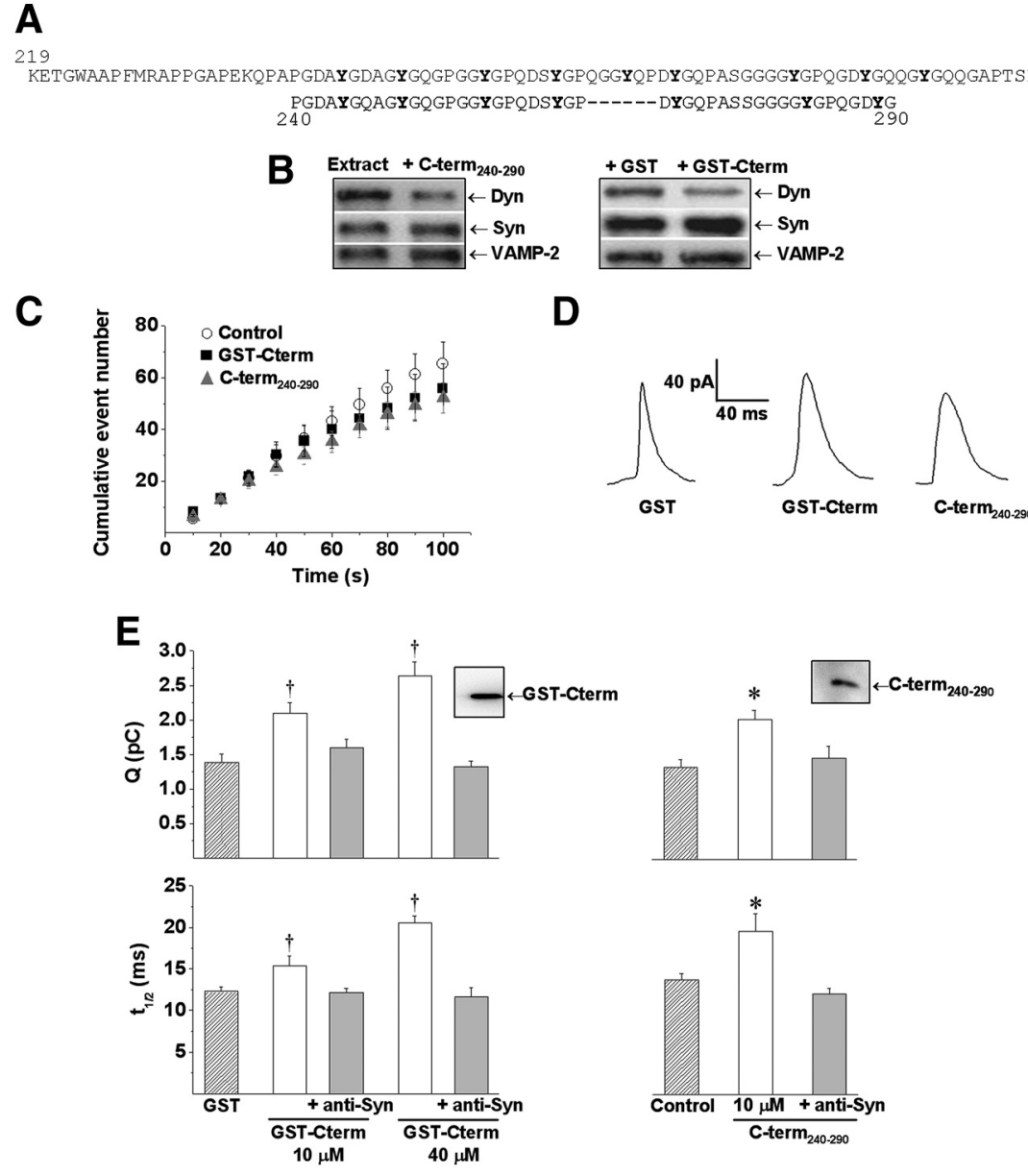

Figure 4. Microinjections of synaptophysin C-terminal derivatives increase duration and quantal size of depolarizationinduced exocytotic events. Chromaffin cells were injected with GST (40 $\mu \mathrm{M})$, GST-Cterm (10 and $40 \mu \mathrm{m})$, GST-Cterm plus

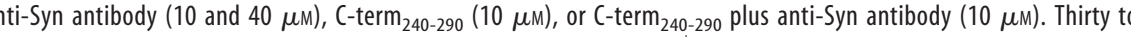
domain of rat synaptophysin (top, gray) and the synthetic peptide (-term ${ }_{240-290}$ (bottom, black). Tyrosine chromaffin C-term ${ }_{240-290}$ GST, or GST-Cterm. Bound proteins were analyzed by immunoblotting with antibodies against Syn, Dyn, and with $40 \mu \mathrm{m}$ GST-Cterm (black square) or $10 \mu \mathrm{m}$ C-term $240-290$ (gray triangles). D, Representative amperometric traces from ells injected with GST, GST-Cterm or C-term ${ }_{240-290}$. E, Averaged values for $\mathrm{Q}$ and $\mathrm{t}_{1 / 2}$. Data are means \pm SEM of averages per cell (12-24 cells from 3 to 5 different cultures). ${ }^{*} p<0.05$ compared with control cells. Insets: Immunoblotting showing that GST-Cterm and C-term $240-290$ are recognized by the anti-Syn antibody.

\section{How does the synaptophysin-dynamin association influence} the quantal release of catecholamines?

The association of synaptophysin with dynamin has been implicated in two different processes. Daly et al. (2000) found that synaptophysin-dynamin complex is necessary for the rapid retrieval of synaptic vesicles, while Liang et al. (2007) proposed that it mediates opioid receptor endocytosis. Here, we propose that synaptophysin-dynamin association has a more subtle effect on the vesicle retrieval mechanism and that its role is to fine-tune the release of catecholamines.

Injections of derivatives of the C-terminal domain of synaptophysin (GST-Cterm and C-term $240-290$ ) increase duration and quantal size of the exocytotic events and slow down the decay of the amperometric spike (Fig. 4). Similar effects were observed when the cells were injected with antibodies against synaptophysin or dynamin (Fig. 3). These kinds of changes in the amperometric parameters could reflect: (1) a shift in the mode of 

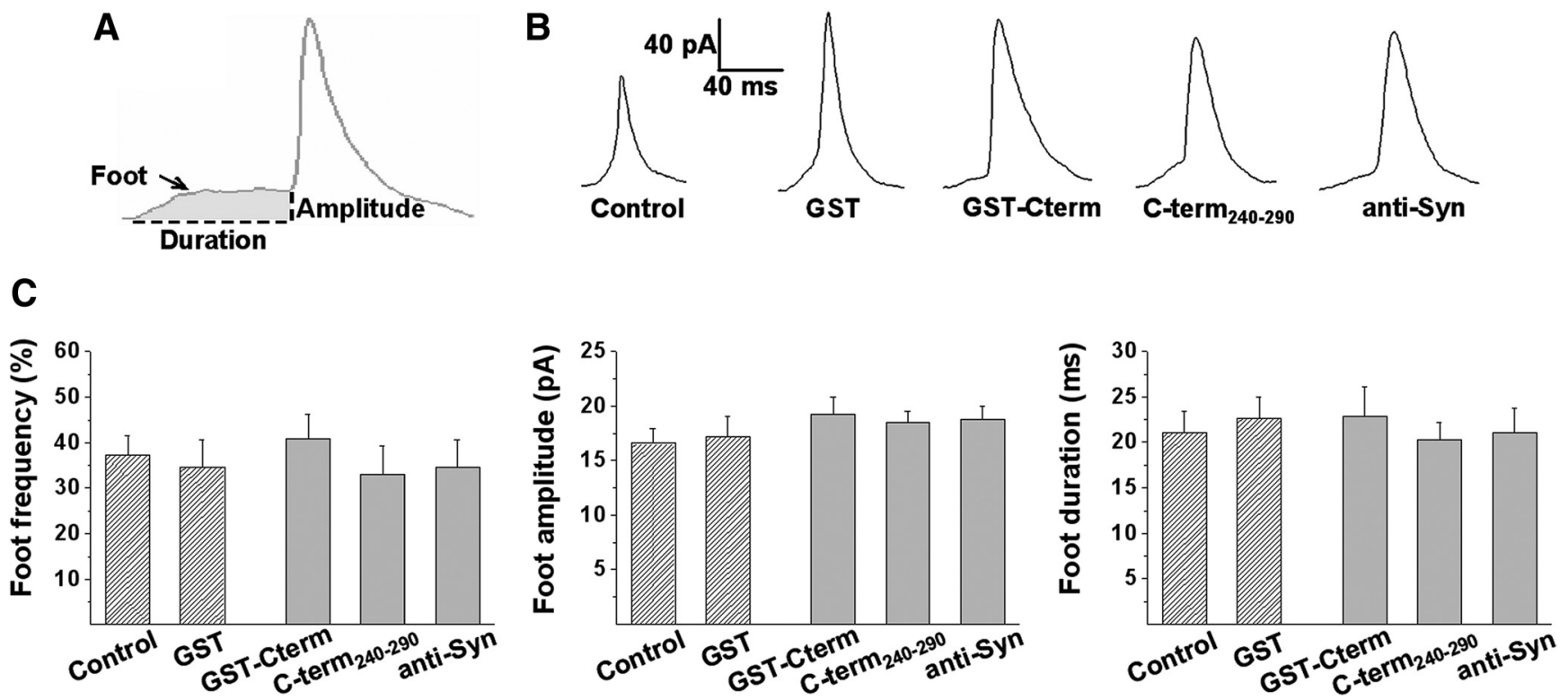

Figure 5. Microinjections of either derivatives of the C terminal of synaptophysin or anti-Syn do not affect the fusion pore dynamics. $A$, Example traces with a long-lasting foot event (shaded area) showing foot amplitude and foot duration. B, Examples of spikes with foot signals from different experimental conditions. C, Averaged values for frequency (percentage of spikes with foot per cell), foot amplitude, and foot duration of amperometric spikes of cells noninjected (Control) or injected with GST (40 $\mu \mathrm{M})$, GST-Cterm (40 $\mu \mathrm{M})$, C-term $240-290$ (10 $\mu \mathrm{M})$, or anti-Syn (10 $\mu \mathrm{M})$. Data are means \pm SEM average per cell (14-22 cells from 3 to 5 different cultures).

exocytosis/endocytosis (Elhamdani et al., 2001; Graham et al., 2002; Barclay et al., 2003; Chen et al., 2005); or (2) an increment in the amount of catecholamines stored in the granules (Colliver et al., 2000). Different modes of exocytosis/endocytosis have been described in neuroendocrine cells, among them the kiss-and-run mechanism. In this mechanism, the fusion pore remains open for a few hundred milliseconds and then abruptly recloses, releasing a small amount of catecholamines, usually observed as "standalone-foot" events in amperometric recordings (Zhou et al., 1996; Albillos et al., 1997; Alés et al., 1999). A dynamindependent kiss-and-run mechanism, whereby dynamin facilitates the closure of the fusion pore, has also been proposed (Elhamdani et al., 2001; Graham et al., 2002). In this scheme, disruption of dynamin function would increase catecholamine quantal size in chromaffin cells, as observed in the present article (Fig. 3E) and by Graham et al. (2002). However, the molecular mechanisms by which dynamin regulates the quantal size is unknown. One possibility is that amphiphysin, one of the most important dynamin-binding partners at the synapse, recruits dynamin to the exocytotic sites. However, seemingly contradictory results have been reported for the effect of disrupting of the dynamin-amphiphysin association. Graham et al. (2002) and Chen et al. (2005) have shown an increase in the quantal size of the exocytotic events, while Fulop et al. (2008) have claimed a decrease. Elhamdani et al. (2006) found no effect. Here, we propose instead that synaptophysin is the partner that recruits dynamin to the chromaffin granules and that higher concentrations of dynamin at release sites will hasten the closure of the fusion pore.

An alternative explanation for the increase in catecholamine quantal size is an increment in the amount of catecholamines stored in the granules. To discard this possibility, we measured chromaffin granule sizes in cells injected with C-term $240-290$. As long as intragranular concentrations of catecholamine remain constant, an increase in its total content should be reflected in a change in the granule size (Colliver et al., 2000; Gong et al., 2003).
As shown in supplemental Figure 1 (available at www.jneurosci. org as supplemental material), the intracellular injection of C-term ${ }_{240-290}$ did not significantly affect the size of either the granule or its dense core. Thus, as long as the concentration remains constant, disruption of the synaptophysin-dynamin association does not increase the intragranular catecholamine content. However, additional analyses are required to completely discard this possibility.

\section{Disruption of synaptophysin-dynamin association does not regulate the initial fusion pore}

It has been observed that synaptophysin forms homomultimers that upon reconstitution into lipid bilayers give rise to voltagesensitive channels (Thomas et al., 1988; Gincel and ShoshanBarmatz, 2002). Similar channel activity was observed when membranes from bovine neurohypophysial secretory granules were incorporated into lipid bilayers (Yin et al., 2002). These observations led to the idea that synaptophysin-formed channels contribute to the fusion pore (Thomas et al., 1988). However, their existence in native cell membranes has not yet been demonstrated. Thomas et al. (1988) and Yin et al. (2002) showed that channel activity decreases when exposed to the same antibody that we used in this current work. Thus, in a scenario that the fusion pore corresponds to synaptophysin-formed channels, their blockade by the antibody should inhibit the exocytotic release of transmitters and/or alter the fusion pore properties. AntiSyn was shown to block peptide release from permeabilized neurohypophysial terminals (Yin et al., 2002) but not to interfere with the depolarization-induced exocytosis in PC-12 cells (Elferink et al., 1993). Here, we observed no effects of the anti-Syn on the spike frequency (Fig. $3 B$ ) or fusion pore properties as monitored by the foot current preceding the amperometric spike (Fig. 5C). On the other hand, disruption of synaptophysin-dynamin association with GST-Cterm or C-term $240-290$ also failed to alter either the fusion pore conductance and stability or the frequency of spikes and foot signals (Figs. $4 B, 5 C$ ). Thus, synapto- 
physin does not appear to regulate the initial fusion pore but, as mentioned previously, after association with dynamin it would become involved in a later step of the exocytosis. This mechanism may play a key role in the tight regulation of hormone release under physiological conditions.

\section{References}

Albillos A, Dernick G, Horstmann H, Almers W, Alvarez de Toledo G, Lindau M (1997) The exocytotic event in chromaffin cells revealed by patch amperometry. Nature 389:509-512.

Alder J, Lu B, Valtorta F, Greengard P, Poo MM (1992a) Calciumdependent transmitter secretion reconstituted in Xenopus oocytes: requirement for synaptophysin. Science 257:657-661.

Alder J, Xie ZP, Valtorta F, Greengard P, Poo M (1992b) Antibodies to synaptophysin interfere with transmitter secretion at neuromuscular synapses. Neuron 9:759-768.

Alés E, Tabares L, Poyato JM, Valero V, Lindau M, Alvarez de Toledo G (1999) High calcium concentrations shift the mode of exocytosis to the kiss-and-run mechanism. Nat Cell Biol 1:40-44.

Annaert WG, Llona I, Backer AC, Jacob WA, De Potter WP (1993) Catecholamines are present in a synaptic-like microvesicle-enriched fraction from bovine adrenal medulla. J Neurochem 60:1746-1754.

Ardiles AO, Maripillán J, Lagos VL, Toro R, Mora IG, Villarroel L, Alés E, Borges R, Cárdenas AM (2006) A rapid exocytosis mode in chromaffin cells with a neuronal phenotype. J Neurochem 99:29-41.

Ardiles AO, González-Jamett AM, Maripillán J, Naranjo D, Caviedes P, Cárdenas AM (2007) Calcium channel subtypes differentially regulate fusion pore stability and expansion. J Neurochem 103:1574-1581.

Barclay JW, Craig TJ, Fisher RJ, Ciufo LF, Evans GJ, Morgan A, Burgoyne RD (2003) Phosphorylation of Munc18 by protein kinase C regulates the kinetics of exocytosis. J Biol Chem 278:10538-10545.

Cameron PL, Südhof TC, Jahn R, De Camilli P (1991) Colocalization of synaptophysin with transferrin receptors: implications for synaptic vesicle biogenesis. J Cell Biol 115:151-164.

Cao H, Garcia F, McNiven MA (1998) Differential distribution of dynamin isoforms in mammalian cells. Mol Biol Cell 9:2595-2609.

Chen XK, Wang LC, Zhou Y, Cai Q, Prakriya M, Duan KL, Sheng ZH, Lingle C, Zhou Z (2005) Activation of GPCRs modulates quantal size in chromaffin cells through G(betagamma) and PKC. Nat Neurosci 8:1160-1168.

Chow RH, von Rüden L, Neher E (1992) Delay in vesicle fusion revealed by electrochemical monitoring of single secretory events in adrenal chromaffin cells. Nature 356:60-63.

Colliver TL, Pyott SJ, Achalabun M, Ewing AG (2000) VMAT-Mediated changes in quantal size and vesicular volume. J Neurosci 20:5276-5282.

Daly C, Ziff EB (2002) Ca2+-dependent formation of a dynaminsynaptophysin complex: potential role in synaptic vesicle endocytosis. J Biol Chem 277:9010-9015.

Daly C, Sugimori M, Moreira JE, Ziff EB, Llinás R (2000) Synaptophysin regulates clathrin-independent endocytosis of synaptic vesicles. Proc Natl Acad Sci U S A 97:6120-6125.

Elferink LA, Peterson MR, Scheller RH (1993) A role for synaptotagmin (p65) in regulated exocytosis. Cell 72:153-159.

Elhamdani A, Palfrey HC, Artalejo CR (2001) Quantal size is dependent on stimulation frequency and calcium entry in calf chromaffin cells. Neuron 31:819-830.

Elhamdani A, Azizi F, Solomaha E, Palfrey HC, Artalejo CR (2006) Two mechanistically distinct forms of endocytosis in adrenal chromaffin cells: differential effects of SH3 domains and amphiphysin antagonism. FEBS Lett 580:3263-3269.

Fisher RJ, Pevsner J, Burgoyne RD (2001) Control of fusion pore dynamics during exocytosis by Munc18. Science 291:875-878.

Fournier S, Novas ML, Trifaró JM (1989) Subcellular distribution of 65,000 calmodulin-binding protein (p65) and synaptophysin (p38) in adrenal medulla. J Neurochem 53:1043-1049.

Fulop T, Doreian B, Smith C (2008) Dynamin I plays dual roles in the activity-dependent shift in exocytic mode in mouse adrenal chromaffin cells. Arch Biochem Biophys 477:146-154.

Galas MC, Chasserot-Golaz S, Dirrig-Grosch S, Bader MF (2000) Presence of dynamin-syntaxin complexes associated with secretory granules in adrenal chromaffin cells. J Neurochem 75:1511-1519.

Gincel D, Shoshan-Barmatz V (2002) The synaptic vesicle protein synapto- physin: purification and characterization of its channel activity. Biophys 83:3223-3229.

Gong LW, Hafez I, Alvarez de Toledo G, Lindau M (2003) Secretory vesicles membrane area is regulated in tandem with quantal size in chromaffin cells. J Neurosci 23:7917-7921.

Graham ME, O'Callaghan DW, McMahon HT, Burgoyne RD (2002) Dynamin-dependent and dynamin-independent processes contribute to the regulation of single vesicle release kinetics and quantal size. Proc Natl Acad Sci U S A 99:7124-7129.

Jahn R, Schiebler W, Ouimet C, Greengard P (1985) A 38,000-dalton membrane protein (p38) present in synaptic vesicles. Proc Natl Acad Sci U S A 82:4137-4141.

Janz R, Südhof TC, Hammer RE, Unni V, Siegelbaum SA, Bolshakov VY (1999) Essential roles in synaptic plasticity for synaptogyrin I and synaptophysin I. Neuron 24:687-700.

Kawagoe KT, Zimmerman JB, Wightman RM (1993) Principles of voltammetry and microelectrode surface states. J Neurosci Methods 48:225-240.

Knaus P, Betz H (1990) Mapping of a dominant immunogenic region of synaptophysin, a major membrane protein of synaptic vesicles. FEBS Lett 261:358-360

Leube RE, Kaiser P, Seiter A, Zimbelmann R, Franke WW, Rehm H, Knaus P, Prior P, Betz H, Reinke H, Beyreuther K, Wiedenmann B (1987) Synaptophysin: molecular organization and mRNA expression as determined from cloned cDNA. EMBO J 6:3261-3268.

Liang YJ, Wu DF, Yang LQ, Höllt V, Koch T (2007) Interaction of the muopioid receptor with synaptophysin influences receptor trafficking and signaling. Mol Pharmacol 71:123-131.

Lindau M, Alvarez de Toledo G (2003) The fusion pore. Biochim Biophys Acta 1641:167-173.

Linstedt AD, Kelly RB (1991) Synaptophysin is sorted from endocytotic markers in neuroendocrine PC12 cells but not transfected fibroblasts. Neuron 7:309-317.

McMahon HT, Bolshakov VY, Janz R, Hammer RE, Siegelbaum SA, Südhof TC (1996) Synaptophysin, a major synaptic vesicle protein, is not essential for neurotransmitter release. Proc Natl Acad Sci U S A 93:4760-4764.

McNiven MA, Kim L, Krueger EW, Orth JD, Cao H, Wong TW (2000) Regulated interactions between dynamin and the actin-binding protein cortactin modulate cell shape. J Cell Biol 151:187-198.

Mitter D, Reisinger C, Hinz B, Hollmann S, Yelamanchili SV, Treiber-Held S, Ohm TG, Herrmann A, Ahnert-Hilger G (2003) The synaptophysin/ synaptobrevin interaction critically depends on the cholesterol content. J Neurochem 84:35-42.

Montiel C, Mendoza I, García CJ, Awad Y, García-Olivares J, Solís-Garrido LM, Lara H, García AG, Cárdenas AM (2003) Distinct protein kinases regulate SNAP-25 expression in chromaffin cells. J Neurosci Res 71:353-364.

Neco P, Fernández-Peruchena C, Navas S, Gutiérrez LM, de Toledo GA, Alés E (2008) Myosin II contributes to fusion pore expansion during exocytosis. J Biol Chem 283:10949-10957.

Obendorf D, Schwarzenbrunner U, Fischer-Colbrie R, Laslop A, Winkler H (1988) In adrenal medulla synaptophysin (protein p38) is present in chromaffin vesicles and in a special vesicle population. J Neurochem 51:1573-1580.

Okamoto PM, Gamby C, Wells D, Fallon J, Vallee RB (2001) Dynamin isoform-specific interaction with the shank/ProSAP scaffolding proteins of the postsynaptic density and actin cytoskeleton. J Biol Chem 276:48458-48465.

Régnier-Vigouroux A, Tooze SA, Huttner WB (1991) Newly synthesized synaptophysin is transported to synaptic-like microvesicles via constitutive secretory vesicles and the plasma membrane. EMBO J 10:358935601.

Schilling K, Gratzl M (1988) Quantification of p38/synaptophysin in highly purified adrenal medullary chromaffin vesicles. FEBS Lett 233:22-24.

Segura F, Brioso MA, Gómez JF, Machado JD, Borges R (2000) Automatic analysis for amperometrical recordings of exocytosis. J Neurosci Methods 103:151-156.

Smith AD, Winkler H (1967) A simple method for the isolation of adrenal chromaffin granules on a large scale. Biochem J 103:480-482.

Spiwoks-Becker I, Vollrath L, Seeliger MW, Jaissle G, Eshkind LG, Leube RE (2001) Synaptic vesicle alterations in rod photoreceptors of synaptophysin-deficient mice. Neuroscience 107:127-142.

Südhof TC, Lottspeich F, Greengard P, Mehl E, Jahn R (1987) A synaptic 
vesicle protein with a novel cytoplasmic domain and four transmembrane regions. Science 238:1142-1144.

Thomas L, Hartung K, Langosch D, Rehm H, Bamberg E, Franke WW, Betz H (1988) Identification of synaptophysin as a hexameric channel protein of the synaptic vesicle membrane. Science 242:1050-1053.

Tixier-Vidal A, Faivre-Bauman A, Picart R, Wiedenmann B (1988) Immunoelectron microscopic localization of synaptophysin in a Golgi subcompartment of developing hypothalamic neurons. Neuroscience 26:847-861.

Valtorta F, Pennuto M, Bonanomi D, Benfenati F (2004) Synaptophysin: leading actor or walk-on role in synaptic vesicle exocytosis? Bioessays 26:445-453.

Wang R, Hosaka M, Han L, Yokota-Hashimoto H, Suda M, Mitsushima D,
Torii S, Takeuchi T (2006) Molecular probes for sensing the cholesterol composition of subcellular organelle membranes. Biochim Biophys Acta 1761:1169-1181.

Yin Y, Dayanithi G, Lemos JR (2002) Ca(2+)-regulated, neurosecretory granule channel involved in release from neurohypophysial terminals. J Physiol 539:409-418.

Zhan RZ, Fujiwara N, Tanaka E, Shimoji K (1998) Intracellular acidification induced by membrane depolarization in rat hippocampal slices: roles of intracellular $\mathrm{Ca}^{2+}$ and glycolysis. Brain Res 780:86-94.

Zhou Z, Misler S, Chow RH (1996) Rapid fluctuations in transmitter release from single vesicles in bovine adrenal chromaffin cells. Biophys J 70: 1543-1552. 